\title{
Cristo más allá del dogma. Hacer cristología en el contexto de las religiones de los pobres ${ }^{1}$ (II)
}

\author{
Aloysius Pieris, S. J. \\ Tulana Research Centre \\ Gonawala-Kelaniya \\ Sri Lanka
}

\section{Tercera parte}

\section{La singularidad irrepetible de Cristo}

\section{El doble kraista sutra}

En un primer momento he presentado el sutra central sobre el que se fundamenta la "cristología de alianza" de la siguiente forma: el amor es el ser de Dios en si mismo, asi como la palabra del nismo Dios hacia nosorros. Más explícilamente lo he arliculado en esla fómula: la palabra de Dios para nosotros es Jesús, quien desencadena y encarna nuestro anor a Dios y al prójino (Primera parte, 2). Ahora voy a desarrollar los contenidos de esta segunda formulación en "dos dogmas" o sutras, mutuamente incluyentes, que muestran con precisión y brevedad la singularidad irrepetible de Jesús como el doble mandamiento del amor de Dios:

I. Jesús es la palabra-de-dos-filos de Dios en conflicto con Mammon.

2. Jesús es la palabra de promesa del Dios de la alianza a los pobres.

(Fórmula 3).

L a primera fórmula expresa el amor de Dios como una batalla de fin de los tiempos (como explicaré más adelante, tomando prestadas palabras de Kíscmann). La scgunda fórmula especifica el amor al prójimo cono servicio decidido y valiente a las víctimas de la explotación (es decir, a las víctimas del latrocinio y la violencia). cspecialmente aquellas con quienes me encuentro en el 
camino (Lc 10, 29-37)'. Así, la realidad de Jesús será experimentada y comprendida - con el corazón y con la mente- en una cristología que sintetiza la ley y los profetas, y que expresa, por lo tanto, la totalidad esencial de la revelación y la salvación.

Estos dos sutras no son afimaciones meramente declaralivas, sino mandatos programáticos, como lo son todas las palabras de Dios, incluido Jesús, el acontecimiento-palabra-supremo. Y como todo mandamiento de Dios es también una palabra de promesa a los pequeños (sutra 2), y de confrontación con cualquier ídolo que usurpa la soberanía de Dios (sutra 1).

El primer sutra enuncia el mandamiento-palabra "ama a tu Dios con todo tu ser", mandamiento que es una promesa que Jesús vino a hacer realidad al abolir "todo tipo de dominación, autoridad y poder" (ICor 15, 24) y al instaurar la soberanía de Dios, después de haber luchado él mismo con el anti-Dios (Mt 4,10). En esa lucha, como dice Ernst Käsemann, Jesús estaba "protegiendo" el primer mandamiento: "Adorarás al Señor un Dios y a él sólo servirás". Este "sólo" le llevó a la cruz. Y este "sólo" sigue siendo la piedra de toque para todos, incluidos nosotros los cristianos".

La cruz es el punto culminante del conflicto, a través del cual se instaura el reino, porque incluso su exaltación como Señor ("pascua") y su efusión del Espíritu ("pentecostés") fueron dimensiones inseparables de su muerte victoriosa, aunque en los evangelios estos dos acontecimientos hayan quedado lemporalizados como episodios sucesivos después de la crucifixión, para que nuestras débiles mentes pudieran absorber este gran misterio de la redención. como si se tratase, por asi decirlo, de una repetición a cámara lenta. La cruz, por lo tanto, revela que la gran batalla del fin de los tiempos ya comenzó, al hacerse carne en Jesús, el hombre de contradicción y de confrontación (Lc 2, 33-35), el conflicto Dios-Mammon (sutra 1), que coincide con la alianza Dios-pobres (surra 2). Gracias a ese "tomar carne", podemos decir, tomando prestadas de nuevo palabras de Käsemann, que "Dios e ídolos constituyen ahora el tema central de la historia del mundo y nadie puede permanecer neutral" ${ }^{\text {. }}$ Un seguidor de Jesús debe entrar al campo de batalla y tomar partido ${ }^{4}$. Así es como hay

1. God's Reign for God's Poor, Capítulo IV.

2. E. Käsemann, "The Eschatological Royal Reign of God", ponencia No. G.04, presenIada en el Congreso de Melbourne (mayo 12-25. de 1980), organizado por la Comision de World Mission and Evangelization of the World Council of Churches, manuscrito, p. 3. Como no tengo una copia de la versión publicada. me veo obligado a citar del manuscrito que el autor amablemente me facilitó cuando vino a visitarme. al regreso del Congreso. Supongo que lo que he citado a partir del texto original no dificre sustancialmente de la versión publicada.

3. Hid. p. 1 .

4. Ignacio de Loyola, Ejercicios Espirisuales, nn. 136-147. 
que entender la encarnación, cuando se la mira desde la aparición pública del conflicto Dios-Mammon en la cruz.

Este lenguaje de conflicto que estamos usando es, a la vez, bíblico y extrabíblico. Aparece de diversas formas en todas las religiones que encontramos en el mundo. Como el conflicto no es con el ateísmo como tal, sino con la idolatría (el servicio a Mammon, que produce grandísimo número de pobres y destruye la faz de la tierra), también puede ser expresado en térninos no-teístas, como ocurre en el budismo, jainismo, taoísmo, etc. Estas religiones apuntan a la liberación sin postular a un liberador. El camino de liberación por el que abogan es de una renuncia radical, no menos radical que la de negarse uno a sí mismo y Iomar la cruz, tal como lo exigió Jesús a sus discípulos, como conditio sine qua non (Mc. 8, 34). Más aín, Jesús, cuyo mismo nombre hace referencia a Yahweh, precisamente cono liberación, apunta a la posibilidad de poder nombrar al Bien último como soteria, más que como soter. Ahora bien, soteria, la bienaventuranza suprema de la libertad interior, implica una larga batalla para liberarse uno a sí mismo de la innata tendencia de absolutizar lo relativo, aferrarse a lo contingente, depender de lo efímero, en una palabra, crear y venerar ídolos. Estas religiones muestran que el no-leísmo puede ser anti-idolátrico, y. consecuentemente, que es posible una expresión no-teísta de la soteria. Quien es anti-Mammon no puede ser anti-Yahweh.

Según csto, nuestro primer surra enuncia, articula, en un lenguaje antropológico y teísta, la enseñanza básica de todas las religiones. Nombrar y reconocer esta enseñanza con una Palabra-Persona, liarnada Jesús de Nazaret (la dimensión cristológica) es nuestra fe específica, que podemos proclamar sólo al tcstimoniar una espiritualidad de bienaventuranza, que es la herencia común de todas las religiones, incluida la nuestra, de acuerdo al sermón de la montaña de Cristo (Mt 5, 3-11) o sus enseñanzas de la llanura (Lc 6, 20-26). Es la espiritualidad del reino de Dios, donde no hay lugar para ídolos.

Desde esta espiritualidad, la opción fundamental común es exactamente lo que entendemos por conversión en el senlido de shub (en hebreo, "cambio de dirección") y metanoia (en griego, "cambio de mente"). Es una vuelta radical al reino de Dios y es un requisito fundamental para la salvación. Eso es lo que deliende cada una de las religiones dentro de su propio paradigma, y cso es también lo que la conciencia humana, independientemente incluso de cualquier religión, exige como camino a la felicidad, es decir, a la bienaventuranza. De ahí que, el centro iluminador primordial de cualquier diálogo y colaboración interreligiosa deba ser nuestra respuesta a la común llamada del reino de Dios para el que también existen diversos nombres. Puesto que tal llamada implica una vuelta al ideal fundamental de la liberación, por el que abogan todas las religiones, la conversión es lo más opuesto al proselitismo. Es más bien, una conlirmación recíproca de la común orientación liberadora de la religión del uno 
para el otro, así como una llamada a volver a los orígenes liberadores de la propia religión.

Dentro de esta llamada universal al reinado de Dios (enunciada en el primer surra), hay muchas vocaciones específicas, como lo expresan las diversas religiones. Este es el siguiente paso en nuestro diálogo inter-religioso, y es importante para descubrir lo que realmente distingue nuestras respectivas fes. La misión específica de cada religión, sin embargo, es tal que no puede anular la vocación común de todas las religiones. Ni la especificidad cristiana, ni la característica específica de cualquier otra religión puede ser tal que contradiga la Ilamada universal del reino de Dios, por muy diferente que sea la forma en que se formule el primer surra.

De hecho, cada religión, en sus concreciones sociológicas, es juzgada a parlir de su propia soleriología. Así, la soleriología cristiana condena su propia manera de expandir la religión con la ayuda de poderes coloniales; el trato que ha dado a los judios, su secular y permanente injusticia hacia las mujeres, su incomprensión y persecución, en el pasado, de otras religiones en Asia. Lo mismo puede decirse del judaísmo, del hinduísmo. del budismo y del Islam. Cada religión codena sus propias desviaciones institucionales a partir de su propia espiritualidad lundamental. De ahí que la espiritualidad común, expresada en el primer sutra, es también el criterio común no sólo para la auto-crílica dentro de cada religión, sino también para la crítica mutua entre las religiones. Esta es una importanle aventura ecuménica.

El cristianismo debe apreciar la especificidad de otras religiones, pero también tiene que identificar lo que lo distingue de ellas, o, dicho con mayor precisión, lo que sintetiza las diversas características que lo diferencian de ellas.

En la aulocomprensión del cristianismo bíblico. su misión específica queda expresada en el segundo kraista sutra: Jesús es la palabra de promesa de la alicinza de Dios con los pobres.'. ¡Una Iglesia que no cumple ese mandato de Dios no podrá presentarlo, en forma prominente. en su cristología! Y cs que si el primer sutra implica el principio de que "no hay salvación fuera del reino de Dios", el segundo sutra lo agudiza: "no hay salvación fuera de la alianza de Dios con los pobres". Esta profundización especílica de la misión es lo que constituye la evangelización especifica confiada a los cristianos. Es la llamada a dar lestimonio de ello y, asi, a proclamarlo.

Ya he explicado las implicaciones espirituales y misioneras de este doble "dogma" cristológico en el pequeño tratado citado antes, en el que he reformulado el doble mandamiento de Dios como dos principios, mutuamente

5. He intentado responder a la objeción de M. Amaladoss a esta alirmación ell el apéndice de God's Reign for God's Poor. pp. 8.3-90. 
incluyentes: (a) allí donde Dios es amado y servido, son los pobres, no la pobre$z a$, los que mandan; y (b) alli donde los pobres son amados y servidos, Dios es el que manda, no Mammon. Ahora voy a hacer algunas observaciones a estos dos principios.

La creencia en un Dios que opta por los pobres, invitando a todos a hacer la misma opción, no tiene por qué ser algo exclusivo de la revelación b́blica. Pero el tipo de Dios que se ha revelado en Cristo en el calvario ha traspasado el umbral de lo "correcto", porque en la cruz Dios se ha atado él mismo a una Promesa, una promesa que es Cristo crucificado y resucitado. Esta promesa, y el modo extremo de llevarla a cabo, parece ser una exageración al moderado (así como fue escándalo para judíos y locura para gentiles). En esto consistc, sin embargo, la singularidad irrepetible de Jesús y la singularidad irrepetible de la misión que confía a aquellos que afirman, públicamente, seguirlo. Esta promesa y su cumplimiento explican la historia de salvación, en la que todos son llamados a participar como co-creadores. Somos enviados a proclamar esta misión como palabra de Dios a todas las naciones.

Desde la primera ley del amor —el amor radical a Dios-, que es nuestro primer sutra, la razón es evidente. El reino de Dios, es decir, una sociedad en la que sólo Yahweh (y ningún otro dios) reina, se caracteriza por la ausencia de una clase social de pobres (DI 15, 4-5). El pecado (como alienación con respecto a Dios), o, dicho con mayor precisión, como idolatría (culto a los Baales, Molocks), aparece en sociedades piramidales (como en los imperios de Egiplo y Babilonia, Grecia y Roma, y en sus homólogos de la actualidad), donde una pequeña clase, que vive en la abundancia, florece a costa del sudor, la sangre y las lágrimas de una masa de esclavos, cuyos gemidos claman por la intervención de Yahweh (Ex 3, 7ss). Sólo Yahweh es el dueño de la tierra y todos los seres humanos no son más que extranjeros y administradores (Lev 25, 23). Por eso, no pueden esgrimir ningún lítulo de poder para privar a otros de las bendiciones materiales de Dios.

El plan de Yahweh para estos esclavos no era solamente que se liberasen de la esclavitud, sino que llegasen a formar una sociedad alternativa, que se distinguiese por una administración justa sin propiedad absoluta (de los medios de producción) y basada en una nueva forma de economía (oiko-nomia, "el llevar la casa" del mundo), una sociedad en la que las prescripciones del jubileo (Lv 25) frenasen la tendencia a constiluir una jeraquía piramidal". La sagrada ley de Dios garantiza un modo humano de gobernar, que permite que sea sólo Dios quien reine (cfr., por ejemplo, Di 11-15). Como lo ha mostrado Lohfink, incluso

6. En el apéndice anexo a este articulo hablo del acto reconciliatorio de Cristo en la cruz, en términos de la dimensión social de la redención, que está implicada en el código del jubileo. 
el nuevo testamento supone que la justicia y la igualdad se hacen presente en la medida en que la soberanía de Dios se hace visible en una determinada sociedad. $Y$ a la inversa, el pecado se manifiesta en la injusticia, en la medida en que Yahweh no es la norma de vida, todo lo cual sugiere la necesidad de establecer un nuevo orden económico que comesponda a una visión de la sociedad como la que hemos descrito'.

Para reafirmar el regir de Dios, el segundo sutra insinúa que la palabra divina de promiesa hizo una opción de clase, en el mismo proceso de hacerse humano, (esopeinosen), lo cual se hace evidente al morir la muerte de un esclavo criminal (Fil 2, 5-11). De este modo, la palabra se hizo pecado en su manifestación más cruda, de modo que, como víctima de la injusticia (la idolatría perpetrada por los fanáticos religiosos en connivencia con los lanáticos políticos), puede exponerse a sí mismo en la cruz como la verdad desnuda. Esto quiere decir que la pobreza infligida a los muchos por la codicia de los pocos es una blasfemia contra Dios, porque profana lo humano y lo cósnico. en lo que el Dios de los pobres ha puesto su tienda. Jesús, a través de esta opción por los pobres, demostró que no era él quien había blasfemado al reclamar para sí autoridad divina, sino que fueron precisamente sus acusadores quienes blaslemaron contra Dios, al poner al César (Jn 19, 15) en lugar de aquel que, en la fe tradicional de Israel, iba a ser el único Dios y Señor de todos los tiempos (Ex $15,18)$ y a quien, apelando al poder del César, lo pusieron en la cruz como en el trono de un impostor. Que lo blasfemasen como Dios y que lo profanasen como humiano era el único camino que le quedaba a Jesús para realizar en sí mismo el gran sueño de Dios y de los pobres ( $L c$ 4, 18-21), que ya había sido prometido en el Tercer Isaías $(61,1-2)$. Fue la consecuencia inevitable de haberse atado a la alianza con los pobres.

En Cristo, por lo tanto, Dios experimentó el pecado como el fruto amargo de la idolatría, al distanciarse de su propio ser Dios. Experimentó la desintegración lípica de toda carne no redimida, en un cuerpo quebrado, mostrando un corazón roto, el fracaso de la comunión entre Dios y la palabra de Dios, entre el Padre y el Hijo". ¿Dónde estaba el Aliento que constituía la relación vital entre el Hablante y lo Hablado? "Padre ¿por qué me has abandonado?". Lo que partió a Dios en dos y dejó ir al Espíritu, creando el abismo en el seno de Dios, por así decirlo, fue nuestro pecado. Y, en retrospectiva, fue también nuestra Felix culpa. pues el Espíritu que, desde su bautismo, había estado actuando en Cristo, escapó ahora del cosiado traspasado de su cuerpo quebrado y se derramó como el agua que da vida, haciéndonos vivir con él en un sólo cuerpo, elevándonos al Padre.

7. Norberl Lohfink, S. J.. "The Kingdom of God and Economy in the Bible". Communio, 13 (oloño 1986), 216-231.

8. Jürgen Molımann. The Crucified God, SCM Press, Londres. 1974, pp. 151-153. 
La muerte de Dios fue lo que nos trajo el Aliento de vida. Así como Dios murió y resucitó en Cristo, así también nosotros hemos muerto y resucitado con Dios en Cristo. Estos dos acontecimientos revelan, respectivamente, la realidad de ser-Cristo (Christhood), que define la singularidad irrepetible de Jesús, y el discipulado que define la llamada del cristiano (como se explicará más adelante en el $\mathrm{N}^{\circ}$. 2). Así es como hablamos de Dios desde el curnplimiento de la promesa en la cruz. $\mathrm{Y}$ a eso es a lo que llamamos cristología.

La cruz, por lo tanto es viernes santo, domingo de pascua y pentecostés, todo en uno. La promesa se realizó al costo de un Dios que amó a los perdedores de este mundo tan apasionadamente que, para ganar para ellos su reino. sufrió el fracaso con ellos. Pues no había otra manera digna de Dios de confundir a los poderes de este mundo. Gracias a este acontecimiento, somos un pueblo de la alianza, que proclamamos a Cristo como la "palabra de promesa", que viene de Dios a los pobres, en respuesta a la "palabra de protesta", que sube de los pobres a Dios. Cristo es ambas palabras en una: la palabra de aliento ("portadora de Pneuma") que, a la vez, habla $a$ las victimas de Mammon, y habla desde dentro de ellas, cualquiera que sea su religión. Este Dios, que nunca pide a los pobres cambiar sus religiones, sino sólo unirse a él, en la lucha contra la idolatría, que habla en ellos y a través de ellos, es en verdad "buena noticia para los pobres". Proclamarla en obras y en hechos es nuestra misión especifica. Es la esencia de nuestra cristología.

Más aún, el Cristo, en cuanto es revelado en la cruz a los asiáticos, es verdaderamente el Cristo asiático, no sólo porque Jesús de Nazaret fue concebido y nacido asiático, sino, con mayor propiedad, porque su cuerpo visible. en que revela la alianza, son los pobres de la tierra, quienes en su mayoría son nocristionos y asiáticos. Escuchado desde la cruz, su clamor no es el eslogan triunfalista que se repite muchas veces en documentos recientes de la Iglesia, "Asia, abre tus puertas a Cristo", sino "Iglesia abre tu corazón y tus posesiones a los pobres, pues lo que haces con ellos lo haces conmigo. Yo soy ellos".

\section{La cruz y la singularidad irrepetible de Jesús}

Ahora estamos en condiciones de profundizar en la respuesta a la pregunta de la así llamada "singularidad irrepetible de Crislo". De hecho, ya he explicado lo que a mi entender es la singularidad irrepetible del cristianismo, y también. en buena medida, el significado único e irrepetible de Cristo, usado éste como un título de Jesús. Quisiera aclarar que la frase "singularidad irrepetible de Cristo" carece de sentido. Lo que hay que buscar es "la singularidad irrepetible de Jesús", pues, al hacerse Cristo, Jesús pone de manifiesto su singularidad irrepctible. Cristo es el nombre con el que se expresa más repetidamente en la escritura y en la tradición la singularidad irrepetible de Jesús. El ser-Cristo de Jesús expresa su singularidad irrepetible. El lipo de palabra que es Jesús (como ha 
quedado expresado en los dos kraista sutras) lo recalca audazmente, como lo hemos demostrado. Ahora quisiera indicar más explícitamente cóno y dónde esta singularidad irrepetible de Jesús, expresada en su ser-Cristo, se devela al mundo.

Ante todo, pongámonos de acuerdo, en que, a diferencia de otros títulos, esta designación mesiánica -Cristo- parece ser el único lítulo del que ha quedado registrado que Jesús aceptó durante su vida terrestre. aunque le diese una nueva interpretación". Pues inmediatamente después de admitir su ser-Cristo - cuando cllo fue reconocido públicamente por Pedro" en términos de su inminente crucifixión, y muy poco después también definió el discipulado de sus seguidores en términos de cruz (v. 34). La cruz no es sólo la salvación que nos ofrece Cristo, sino también nuestra participación —en alianza con él- en su acto redentor. De esta manera, ser-Cristo y discipulado convergen en la cruz.

La implicación es clara: no puede haber un Cristo sin la cruz; y a la inversa Cristo no puede estar ausente altá donde se carga una cruz en cualquier lugar del mundo, sea cual fuere la religión de quien la carga, pues él o ella es un discípulo de Jesús. Por esta razón hemos excluido las cristologías de los curialistas, de los liherales y de la élite asiática cristiana, pues han tratado de separar lo que Dios ha unido: Cristo y la cruz, el discípulo y la cruz. Es en la cruz donde Jesús y sus discípulos forman el cuerpo que es Cristo.

La insistencia en que la cristología debe girar alrededor del acontecimiento de la muere-resurrección que tuvo lugar en la cruz (lo que define la singularidad irrepetible de Jesús así como la especificidad del discipulado) se ha inspirado en los dos aspectos de Cristo que coinciden en la cruz, que es lo que ahora queremos analizar:

a) la quasi-identidad de la muerte y resurrección de Jesús, en el sentido de que su muerte fue de tal naturaleza que merecía la resurrección como una diinensión suya propia inseparable, $y$

b) el hecho de que, a través de este acontecimiento de muerte-resurrección, Jesús fue constituido "Hijo de Dios" y "Espíritu santificante" (Rom 1, 3-4).

Que la muerte y resurrección de Jesús no fueron dos acontecimientos separados y separables, sino "dos aspectos de un único misterio" al que le perlenece una "unidad indisoluble", es algo que las Escrituras cristianas enseñan con toda claridad". Se puede argumentar que se requería un intervalo entre muerte y

9. Ver C. F. D. Moule The Origin of Christology, Cambridge University Press. Cambridge, 1977, segunda reimpresión 1979. p. 31 ss.

10. También ante el Sanedrín (Mc 14, 62), como lo hace notar Moule, ibid., p. 33.

II. Stanilas Lyonnet, S. J.. "Redemption Through Death and Resurrection", en M. R. Ryan (edilor), Contemporary New Testamem Studies, Liturgical Press. Collegeville. Minnesota, 1965, pp. 377s. 
resurrección, dadas las "condiciones humanas", porque "de otra liorna su mucrte no hubiese sido considerada como verdadera muertc"'l?. ¿Pero signilica cslo. necesariamente, que la resurrección luvo lugar un par de días después, como lo sugieren los relatos? Pcro las "condiciones humanas" que se aducen para que sea necesario un intervalo visible y verificable entre los dos acontecimientos no hacen de cse intervalo algo intrínseco a los acontecimientos en sí mismos. sino a mestra naturalcza humana. Nucsiras débiles lacultades de comprensión requicren una como repetición a cámara lenta del acontecimiento. Pero según la lógica anles aducida, ¿no sería un problema insuperable alirmar la perınanencia durante días de un cadáver después de su exaltación en la cruz (es decir, la resurrección). a no ser que sc entienda ćsta como la resucitación de un cadáver? De hecho, toda carne resucitará al modo como lo hizo Jesús, es decir, en un "cuerpo espiritual" con relación al cuerpo que verdaderamente muere, es decir, un cucrpo que retorna a la tierra de la que provino, como una semilla que muere para tlorecer después en lorma de vida (1Cor 15, 38-44).

Lo que decinos de la unidad inseparable de la muerte y resurrección vale igualmente para la elusión del Espíritu. que también tuvo lugar en la cruz'" La resurrección, como un aspecto de su mucrte, hace de Jesús un Espíritu santilicante (Rom 1, 3-4; 1Cor 15, 45), es decir, Aquel cuya muerte consistió litcralmente en ex-pirar su Vida, que es el Espíritu de Dios. Esta es la razón por lo que su muerte es Vida, es decir, resurrección que ex-pira al Espíritu Santo.

Lo más significativo, aunque los cristólogos no lo reconozcan explícitamentc. es que el acontecimiento de la muerte-pascua-pentecostés constituye la expresión suprema y el momento denso del doble nandamiento-palabra de amor a Dios y al prójino. vivido en plenitud por Jesús en la cruz, como la esencia de su ser-Cristo. Lo que hace salvífico a este acontecimiento pascual (cs decir. lo que lo convierte en el cumplimiento de la promesa divina), es que Jesús abrazó esta forma de morir (que necesariamente implicaba la resurrección y la elusión del Espíritu) en obediencia amorosa al Padre (Fil 2, 8), tal como lo exige el primer mandamiento del amor, e igualmente en su desbordante amor a la humanidad (Ef 5, 2), en conformidad con el segundo mandamiento del amor. Ese acto supremo de Jesús, encarnando la doble palabra de promesa en su "paso" (vidamuerte-vida), es lo que reconcilió a la humanidad con Dios. Al decir esio, no estoy más que haciendo explícito lo que ha estado implícito en la tradición reológica (no en la cristo-lógica) de occidente, que siempre atribuyó la redención obtenida por Jesús a su obediencia y amor. manifestados en la muerte de cruz. más que en la encarnación.

12. Ibid. p. 377.

13. Véase, John O'Donnell, S.J., "In Him and Over Him: The Holy Spirit in the Lile ol Jesus", Gregorianum, 70/1 (1989), 35ss. 
Santo Tomás no cesa de repetir esta verdad. Al comentar, por ejemplo, Romanos 5, 10, observa: "No fue la muerte de Cristo, simplemente en cuando muerte, lo que de tal manera agradó al Padre que reconcilió al hombre ( $y$ a la ınujer) con él. Dios no se alegra en la muerte de los vivientes (Sab 1, 13)". El aspecto de la muerte de Cristo que mereció nuestra salvación fue más bien el hecho de que procedía "de la libertad de Cristo; pues Cristo quiso morir por obediencia al Padre (Fil 2, 8) y por amor a los hombres (y mujeres) (Ef 5, 2)"14.

Esto signilica que Jesús, que muere y resucita en la cruz, no es sólo la Palabra divina que expresa y constituye el doble mandamiento del amor a Dios y al prójimo, sino que es también la palabra humana de obediencia a ese doble mandamiento, que es él, en sí mismo. Esta palabra teándrica (divino-humana) es la que se expresa en el título "Cristo", incorporando en él todos los otros lítulos. Como la cristología clásica ha girado excesivamente alrededor de especulaciones basadas en la unión hipostática (encarnación), pasó por alto esta dimensión constitutiva del ser-Cristo, que Jesús manifestó como su realidad específica, singular e irrepetible. Se presupone, sin duda, que Jesús es la palabra-promesa preexistente, pero sólo como conclusión, no como la premisa mayor. Esa premisa es otra: la filiación preexistente de Jesús (cfr. Rom I, 3) "es ahora visible, por lo que a nosotros toca, a través de la resurrección. Jesús se hizo capaz de compartir su filiación con nosotros". Así lo explica Lyonnct, como también lo hicieron los Padres al comentar este texto's.

Que en la cruz se revelase su filiación y que en ella se hiciese posible muesira participación son dos aspectos de la redención, profesados en casi lodas las iglesias. Hay en esto un consenso nolable, a pesar de que los modos de articular esta verdad sean diversos. En la literatura evangélica popular de grupos que viven en los márgenes de las iglesias protestantes históricas, la cruz (mucrte-resurrccción) es presentada en su doble carácter, implicando tanto sustirución como identificación. Lo primero se refiere a "Cristo muriendo por nosotros" y lo segundo "nuestro morir con él" (hacia la vida) ${ }^{\text {th }}$. Quisiera sugerir que estos dos aspectos corresponden, respectivamente, al ser-Cristo, que define la singularidad irrepetible de Jesús, y al discipulado, que define al cristiano.

En la tradición calólica escolástica esta distinción aparecía en la Jistinción entre redención objeriva y redención subjetiva. La primera es realizada por Cristo (Jesús muerto y resucitado), en su retorno al Padre como la "primicia" de la redención (1Cor 15,20 ), es decir, como quien contiene en sí, vicariamente, la cosecha toda del mundo redimido; la scgunda se relicre a cada cristiano, mu-

14. Lyonnel. op. cit.

15. Lyonnet, p. 375.

16. Ver por cjemplo. Miles J. Stanford. The Principles of Spiritual Growth. Back to the Biblc. Lincoln NE, 1991, pp. 47-51 y passim. 
riendo y resucitando con él en el bautismo (Rom 6, 3-4), basándose en el bautismo de Jesús en la cruz. Así como la crucifixión fue su bautismo (cfr. Lc12, 50), así nuestro discipulado de llevar la cruz es nuestro bautismo. Pues como Pablo lo dijo claramente, nuestro bautismo no es un mero rito, sino un acto personal de participar en el misterio pascual ${ }^{17}$; es realizar nuestra parte de la alianza. Cristo recibe su bautismo muriendo por nosotros y nosotros recibimos el nuestro muriendo con él.

De aquí que, audazmente, mantenemos que lo que es "absolutamente necesario para la salvación" no es el bautismo como un sacramento, sino el bautismo como cumplimiento personal o colectivo de las exigencias crucificantes del servicio (cfr. Mc 9, 35-45 y paralelos). De acuerdo con lo que hemos dicho antes (Tercera parte 1), lo que ahora podemos añadir es que éste es el bautismo que exige la espiritualidad común a todas las religiones. Así, Jesús, el Cristo, exaltado en la cruz y emitiendo el espíritu, permanece como el fundamento de nuestra le en el bautismo común, ofrecido a la humanidad en la cruz, que está universalmente presente en las luchas vitales de la humanidad, en el misterio pascual. disponible universalmente a todas las tribus y naciones, en todas las religiones y culturas.

Así como la Iglesia es llamada a vivir como una expresión sacramental de la humanidad redimida, cuya primicia es Cristo (es decir, Jesús muerto y resucitado), así también el bautismo sacramental es la promesa de alianza, que nos obliga al compromiso martirial (testimonial) de bautizar y hacer discípulos a las naciones (Mt 28, 19), pero ciertamente no a través de un proselitismo, que fue ridiculizado por Jesús (MI 23, 15), sino colaborando con todos los hombres y mujeres de buena voluntad, en la tarea crucial (es decir, "cargando con la cruz") y arriesgada de derribar a los ídolos de las naciones, que representan nuestro in llado ego: ídolos como formas absolutizadas de clase, credo, color, cultura, lengua, género, raza, religión, Estado, Iglesia, poder, beneficio, mercado o cualquier otra cosa que se instale a sí misma como divinidad suprema. Una nación que es liberada de la esclavitud a estos ídolos ha sido bautizada como discípulo de Jesús, pues Yahweh sólo puede reinar donde no mandan otros dioses. En otras palabras, nuestro bautismo constituye nuestra redención subjetiva, no meramente como individuos (por ejcmplo, Rom 6,$4 ; 13$ ), sino también como una comunidad sociopolítica convocada por Dios para participar en el compromiso "secular" del reino de Dios (Rom 12, 1-2)".

17. O’Donnell. pp. 29-33.

18. Veanse las observaciones de Ernst Käsemann en Commentary on Romans, Wm B. Eerdsmans Publishing Company, Grandrapids. Mich. 1980. pp. 325-331. 


\section{Cristo, el cuerpo del Dios trinilario}

La cristología es un discurso sobre el Dios trinitario, que mora en nosotros. Esto ha quedado ampliamente ilustrado en el lenguaje mismo que hemos usado en las discusiones anteriores. No se puede hablar de Jesús como el Cristo con independencia del Padre y del Espíritu, justificando así la asociación de la palabra Cristo a la noción de la trinidad divina que tuvo lugar muy tempranamente en el cristianismo. Después de todo, incluso la doctrina clásica de la trinidad se desarrolló desde la cristología, y no sólo para preservar la unidad entre Cristo y Dios (tanto desde el tema de Dios como desde el terna de Cristo), sino también para corregir herejías que negaban uno u otro aspecto, lo cual tuvo como resultado que el lenguaje filosófico que se llegó a usar en el contexto de una prolongada clarificación adquirió gradualmente un carácter teológico, haciendo que naciese la teología trinitaria ${ }^{19}$. De ahí que sea comprensible que la cristología que he propuesto tenga también su propio modo de expresar nuestra le en el Dios trinitario.

Uno de los frutos más valiosos de la doctrina cristológica clásica de la trinidad ha sido la importante y fructífera noción de "persona", que desde entonces ha permeado no sólo el área de la teología sino también la filosofía y la psicología, especialmente en occidente ${ }^{21}$. El "ser-persona" queda constiluido por una combinación de autonomia y relación, lo cual supone necesariamente el concepto y la realidad de "comunidad", como su complemento correlativo. Así, la comunidad de personas se distingue de una multitud de individuos, y a la inversa, una persona en comunidad se distingue de un individuo en medio de la inultitud, según sea la presencia o la ausencia de relaciones recíprocas. Este modo de pensar es, interesantemente, el resultado y a la vez la contribución de la proclamación del Dios del cristianismo (en cuanto pensado y en cuanto testimoniado) como una comunidad trinitaria de personas, con consecucncias de largo alcance, tanto para la eclesiología (el modelo no-piramidal y no-jerárquico de gobierno eclesial) y la misionología (la misión de re-crear comunidad cn un mundo dividido), como, consecuentennente, para la espiritualidad (la llamada a ser persona en una comunidad, en lugar de permanecer como un individuo en inedio de la inultitud).

Sin embargo, como lamenta Moltmann, occidente ha abandonado la "doctrina social de la trinidad", así como ha lracasado en desarrollar las implicaciones de la perichoresis, de modo que ha caído en un "individualismo auto-posesivo". y cl calolicismo -además- ha abandonado csta doctrina en lavor de un teísmo

19. J. Molımann, The Trinity and the Kingdom of God: The Doctrine of God, SCM Londres. 198 I. p. 129.

20. Alois Grillmeier, Jesus der Christus im Glauben der Kirche: Band 2/I Das Kon:il von Chalcedon Recepzion tand Wieder:spruch (451-518), Herder Freiburg. 1991. p. 9. 
monárquico, que queda al descubierto eclesiológicamente en la evolución que ha ido tomando el episcopado y el papado"'.

En Asia, por nuestra parte, tenemos un problema diferente. En algunos contextos religiosos de las culturas asiálicas, la palabra "persona" tiene una connotación negativa y no es una formulación feliz para apticarla a la divinidad. Se necesita. por tanto, superar esta aversión teológica a la palabra "persona". En efecto, si hay algo nuevo que decir acerca de Dios y si palabras tales como "persona" pueden ponerse al servicio de esta nueva intuición. entonces tales palabras deben ser imbuidas del significado adecuado, para que ayuden a la humanidad a crecer espiritualmente. Esta noción de "persona". descubierta en el a fán de expresar el misterio de Cristo, es una adquisición universal.

Merece la pena el esluerzo de expresarlo en nuestras lenguas asiáticas, no en el sentido filosólico griego, pero si quizás en el sentido gramatical en el que el lérmino "persona" se usa en algunas de nuestras lenguas. Un cristiano puede decir que el Dios de Jesús es capaz de una conversación intra-divina, conversación, pues, no soliloquio. Esto quiere decir que en Dios pudiera darse una referencia en términos de la Primera y Segunda y Tercera Persona, a lo que es conocido en la gramática de la conversación humana, como "Yo", "Tú" y "ElElla". Esto puede ser proclamado, ciertamente. como nuestra le, pues tal relerencia se da en el modo como Jesús habló sobre sí mismo y el Espírilu al dirigirse al Padre. Este triple ingrediente de la conversación interpersonal, que configura y caracteriza la gramática de la mayoría de las lenguas, es bien expresivo en sí mismo, aun sin tener que recurrir a una posterior delínición del término "persona".

Sin embargo, hay que hacer una elección. ¿De qué idioma (lenguaje) vamos a hacer uso como base para expresar en Asia csta le en el Dios trinitario en los términos sencillos, prestados de la gramútica?

De nuevo, la noción helenística que identificaba la "esencia" o naturaleza común de la persona humana cono participación en el Espíritu o Razón universal. y, cmparentada con la anterior, la idea de que la "individualidad" cspecílica propia cstí detcrminada por el cuerpo o la materia propios (considerados como un mal en el helenismo no cristiano), parecen constituir los elementos esenciales de la antropología que determinó la especulación sobre las nociones de "pcrsona" y "personalidad" en la teología occidental. La persona, delinida por Boccio como sustancia individual de naturaleza racional, más cl corolario escoléstico de que es la materia lo que individualiza a la persona, se ha convertido en parle del acervo teologico que subyace a la cristología del presente.

21. Molumann. The Trimiry, pp. 199-201. 
J. A. T. Robinson, a quien he resumido en el párrafo anterior, hace notar que la concepción hebrea de la persona humana es exactamente la opuesta ${ }^{22}$. El factor individualizante no es la materia o el cucrpo (como en el helenismo), sino el espíritu, el ruah de Dios, a través del cual somos llamados por nuestro nombre desde un profundo amor (lo cual quiere decir que cada uno de nosotros es un acontecimiento-palabra único). $\mathrm{Y}$ a la inversa, nuestra naturaleza común no es el espíritu o la razón (como en el helenismo), sino el cuerpo (soma, un cuerpo físico-psíquico al que se denomina psyque y sarx) 2. $^{2}$. Este cuerpo, dice Robinson, "es el símbolo no de individualidad, sino de la solidaridad, que vincula a cada uno de los individuos, por mucho que él (o ella) sea singular e irrepetiblemente divino, en relación indisoluble con el todo de la naluraleza, de la historia y del "orden cósmico"24.

El mecanismo del cuerpo, a través del cual el individuo debe dar respuesta a la palabra, no es algo permanente o exclusivamente suyo. Es siempre, por así decirlo, algo prestado a un ser humano por la raza o la naturaleza: es polvo y al polvo retornará -no sólo una vez, sino continuamente... Este cuerpo lísico-psíquico nunca es un instrumento perfecto del espíritu: tiene que ser redimido y transformado ${ }^{25}$.

Cuando la Palabra se hizo carne (Jn 1, 14), la Palabra asf corporeizada. juntamente con el Dios que la pronunció, así como el aliento divino por el cual fue pronunciada, tenía que estar implicada en la lucha del tiempo final para redimir al cuerpo de su labilidad. Pues el cuerpo significa solidaridad con todo el universo. Así, la solidaridad intra-divina de la trinidad asume la solidaridad humano-social y cósmica, sufriendo dentro del mismo Dios las penas de la carne (desintegración), para reunir todo en un único cuerpo, es decir, la persona cor-

22. J. A. T. Robinson, In the End God, Harper and Row, New Yok, 1968, pp. 95-100.

23. Según esto, la persona humana como psyque y sarx no admite una substancia espiritual, inmulable e inmortal llamada alma, sino que se asemeja a la composición de la persona humana nauna-rupa (nombre-forma), defendida por el budismo. La cuestión del alma humana de Cristo, eterna e inmorlal, jugó un papel significativo en los debates cristológicos. Lynn A. de Silva. quien aceplaba la doctrina de los budistas de la "no-alma" (anatra-anasma), y que no le parecís tan radical como la doctrina de la no-alma del polvo eres y al polvo has de retornar del cristianismo. insistía en el pneuma-ruah corno lo que hace a una persona humana capaz de buscar y enconIrar el Sumo Bien. (L. A. de Silva, The Problem of the Self in Buddhism and Christianity, Colombo, 1975, pp. 85-96). Esloy convencido de que en el conlexto de una religion no-teísta como el budismo, en el que la liberación es tridimensional. como en toda religión, el pneuma puede ser expresado como la potencialidad otorgada para el Bien Salvífico (véase A. Pieris. Love Meets Wisdom. A Christian Experience of Buddhism, Orbis Books, New York, 1988, pp. 131 ss).

24. Robinson, In the End God, p. 98.

25. Ibid., p. 99. 
porativa, Cristo, como ya lo hemos visto antes. La tendencia temprana de tratar a Cristo y a la trinidad como realidades convertibles (en la liturgia y en la teología) -vuclvo a repetir- estaba muy justificada. Pues Cristo es el Dios trinitario que entra en solidaridad con nuestra carne para redimirla en un "cuerpo plenamente transformado por el espíritu" (soma pneuniatikon). La resurrección, nuestra liberación linal, es precisamente eso. Es nuestro cuerpo, en cuanto ha alcanzado, en Cristo, nuestro futuro, cl mundo que ha de venir. Somos Ilamados a anticipar el futuro como el encuentro actual con el Dios trinitario, en el "cuerpo espiritual", que es Cristo, en el que somos reconciliados unos con otros y con Dios (Rom 5, 10-11; 11, 15; 2Cor 5, 17-21; Col 1, 19-25; Ef 2, 14-17). Y el único camino para comunicar este misterio de reconciliación es ser nosotros mismos un cuerpo con Cristo, quien es la comunidad del futuro, un cuerpo inutuamente reconciliado no jerárquico, de acuerdo a la imagen del Dios Irinitario.

De hecho, en Asia ha estado en boga una experiencia litúrgica asiática del Dios trinitario como "Silencio", la "Palabra" y la "Armonía" entre "Palabra y Silencio", anticipando (proclamando, por lo tanto) la Iglesia de los reconciliados, libre de dominación, la comunidad del fínal de los tiempos, del Cristo total, a quien esperamos como a nuestra salvación ${ }^{26}$.

\section{Apéndice}

Nos parece importante y relevante para la actualidad hacer una observación sobre la dimensión social de la redención, que es parte integrante de la cristología de la alianza. El fundamento de esta cristología, que afima la singularidad irrepetible de Jesús, en su ser-Cristo, es la comprensión correcla de la expresión remisión de pecados o de las deudas. Esta expresión ha recibído cspecial atención en un estudio reciente, que, en mi opinión, tiene consecuencias importantes para la cristología que he propuesto, en este artículo. En un primer momento voy a resumir los resultados de esta investigación.

Los dichos evangélicos sobre la remisión de pecados son de tres tipos. Algunos de ellas asocian la remisión de pecados claramente a la muerie de Jesús. En orros, Jesús declara simplemente que los pecados son perdonados en hase a su propia autoridad, sin hacer ninguna referencia a su muerte. Existe todavia una tercera categoría de dichos en los que no se hace referencia ni a la muerre de Jesús ni a su poder de perdonar pecados, sino simplentente al modo como el ser huntano tiene que relacionarse con Dios y con el prójimo. En este último grupo (incluidas algunas parábolas), el per-

20. A. Pieris S. J.. "A Liturgical Anticipation of a Domination-Free Church: The Liberating Story of an Asian Eucharist", Tissa Balasuriva Felicitation Volume. Ed. B. Silva et al., CSR. Colombo, 1997, pp. 69-82. 
donar las deudas-pecados a otros se convierte en condición de que Dios perdone los pecudos propios. Mi redención subjetiva, por así decirlo, es el perdón que generosaniente otorgo a mis ofensores. La conclusión de este estudio sobre los dichos acerca del perdón recibido de Dios a cambio del perdón otorgado a mi prójimo indica que a Jesús se le hace hablar aquí según las creencias escatológicas de su tiempo: la expectativa convencida de la utopia social en la era del jubileo (Lev 25,8-25). cuando se establezcan relaciones justas en la comunidad humana, manifestará la liberación (del fin de los tiempos) prometida por Yahweh"

Sería lamentable que, al no hacer referencia a Jesús o a su muerte en la cruz csle tercer grupo de dichos sobre el perdón. se llegase a pensar que la salvación es posible sin el bautismo de Cristo en la cruz, un hautismo que anticipa el hautismo de las naciones. Por eso queremos hacer la siguiente reflexión.

El primer grupo de dichos conlima lo que ya ha quedado establecido, y, por lo tanto, no necesita comentario. En el segundo grupo, se nos dice que Jesús ejercita la auloridad divina, recibida del Padre precisamente para perdonar pecados que, al parecer, no se cometían consciente o directamente contra él. Mi opinión es que Jesús podía perdonar pecados de esa forma porque, debido a su naturaleza singular e irreperible, estaría actuando representando a Dios y al prójimo, contra quienes se peca en todo acto que viola el doble mandamiento del amor. Perdonar en nombre de aquellos a quienes se ha ofendido. por lo tanto, es la prerrogativa singular e irrepetible de Jesús. Sólo él, que es a la vez nuestro Dios y nuestro prójimo, es capaz de este gesto redentor. Este es el corazón mismo de la crisıologfa de alianza.

Por lo que toca al tercer grupo, debemos recordar que el perdón mutuo, como condición y anticipación del perdón escatológico ofrecido a la humanidad de parte de Dios, aparece en su máximo momento revelador cuando Cristo, en representación de todos nosotros, es decir, como la "primicia" de quienes han sido reconciliados con el Padre, generosamente perdona desde la cruz a todos sus enemigos. De hecho, si estas frases de Jesús sobre el perdón de los pecados se consideran desde la perspectiva "promesa-cumplimiento", la amnistía universal que Cristo proclamó en la cruz se convierte en el sello de la alianza, del cumplimento de la promesa de salvación. del establecimiento delinitivo de la era jubilar".

27. Mauro Pesce (con Adriana Destro), "La Remissione dei Pecatti nell"escatologia di Gesu" Annali de Stria dell'Esegesi 16/1 (enero-junio 1999), 45-76.

28. Pesce (op. cil., p. 60, nota 39) remite a un estudio sobre los mismos textos desde la perspectiva promesa-cumplimiento: A Pitta, L'Anno della Liberazione. II Jubileo e le sue instanze bibliche. Ciniosello Balsamo, Edizioni Sao Paulo, 1998. No sé si este estudio confirma lo que digo aqui. 
Quisiera añadir, sin embargo, que lo que rige la utopía social de la era jubilar es la ley innata de la "responsabilidad recíproca", no los derechos individuales o colectivos que, si se les da prioridad, tienden a dividir la sociedad en exigencias y contra-exigencias. El abandono por parte de Caín de su responsabilidad hacia la vida de su hermano ("soy yo a caso el guardián de mi hermano y hermana?") fue una violación flagrante de la alianza original, según la cual toda la creación, incluidos nuestros prójimos humanos, fueron confiados a nuestro cuidado personal y colectivo. La advertencia "gobiemen la tierra" (Gen 1. 28), significaba: "sean corresponsables junto conmigo de toda la tierra", lo cual incluye el cuidado y desarrollo de todas las criaturas infrahumanas (cfr. Gen 2, 5.15).

De aquí se desprende que la fundamentación escriturista de una teologla de la alianza, en oposición a la comúnmente aceptada teología de los derechos, consiste en lo siguiente: ser portadores de la imagen de Dios significa participar en la responsabilidad de Dios. La teorla de los derechos no puede justificar la responsabilidad humana hacia la fauna y la flora, que "no tienen derechos puesto que no son personas", y por lo tanto no son portadores de "la imagen y semejanza de Dios". Este es el callejón sin salida al que necesariamente conduce la teoría de los derechos. Así, en una cristología de la alianza (basada en las obligaciones recíprocas de la promesa, más que, primariamente, en los derechos), la cruz es vista como el lugar en el que Jesús restauró esta alianza primordial de co-responsabilidad, reconciliando por su muerte-resurrección no sólo a los seres humanos entre sí y con Dios, sino también reintegrando a todo el cosmos que había quedado alienado con respecto a Dios y a la humanidad. a través de nuestra irresponsabilidad personal y colectiva.

Al llegar a este punto tengo que revisar brevemente un argumento que he propuesto en otro lugar. He cuestionado el paradigma de fe, justicia, que tiene sus raíces en la noción jurídica romana de justicia, más que en la enseñanza biblica de los imperativos de la alianza, sedega y misphat, y, por lo tanto, me he preguntado si en la "teología de derechos humanos" había algún lugar para el perdón de las dcudas. como lo exigen las prescripciones del jubileo" ${ }^{20}$. El debate que provoqué sobre este asunto, hace algunos años ${ }^{\text {w. }}$. ha vuelio a plantearse en forma distinta como el contraste entre los juicios de Nurenberg de la Alemania de la posiguerra y la Comisión de Verdad y Reconciliación, de la Sudálrica post-Apartheid, los primeros basados en la "justicia retribuliva" de la tradición de derechos, y lo segundo basado en la "justicia restaurativa" de la tradición alricana ubuntu. Esto ha sido clarilicado en el libro de Desmon Tutu que lleva el título profético de No Future without Forgiveness".

29. God's Reign for God's Poor, Capítulo 2, especialmente página 22.

30. Véase, Fire and Waser, capítulos 8 y 10. Estos capítulos son texios escritos en los ochenta.

31. Desmon Tulu, No Future Wishous Forgiveness, Doubleday, New York, 1999. 
Según la Comisión de Verdad y Reconciliación, el perdón no significa una amnesia nacional de los horrendos crimenes cometidos contra víctimas indefensas, como han pensado, erróneamente, algunos criticos, sino un proceso de reconciliación en el que quienes han cometido crímenes son llamados a reconocer sus pecados ante el pueblo, en un foro público, y así reciben el perdón generosamente otorgado por las víctimas. Esa especie de justicia restaurativa, que la tradición tribal de Africa ha mantenido en muchas otras ocasiones, con anterioridad a la Comisión de Verdad y Reconciliación ${ }^{32}$, es lo que para la federación tribal de Israel constituja lo distintivo de una sociedad en la que regía sólo Yahweh. Esta comunidad —dentro de la humanidad—, vislumbrada en el códjgo del jubileo, mutuamente reconciliada y recíprocamente perdonada, es lo que nació cuando se derramó el Espíritu del costado traspasado del Dios crucificado. Esta eclesiogénesis expresa la convergencia de toda la humanidad hacia la comunidad trinitaria, que fue revelada en la cruz, cuando el Hijo restauró toda la creación en el amor, perdonador y otorgado gratuitamente, del Padre maternal, para quedar para siempre bajo la soberanía unificadora del Espíritu Santo.

32. Ibid., p. 32. 